\title{
PERSEPSI REMAJA MENGENAI KESEHATAN REPRODUKSI, KEHAMILAN DAN PERNIKAHAN DI USIA REMAJA: STUDI KUALITATIF PADA SISWI SMA PEDESAAN DAN PERKOTAAN
}

\section{Listyani Hidayati1,2, Nunung Cipta Dainy², Eneng Nunuz Rohmatullayaly ${ }^{3}$ dan Dodik Briawan ${ }^{4}$}

${ }^{1}$ Prodi Gizi Fakultas Ilmu Kesehatan Universitas Muhammadiyah Surakarta Jl. A. Yani, tromol Pos I, Pabelan, Surakarta ${ }^{2}$ Mahasiswa Program Studi IImu Gizi Manusia Pascasarjana IPB ${ }^{3}$ Mahasiswa Program Studi Biosains Hewan Pascasarjana IPB ${ }^{4}$ Dosen Departemen Gizi Masyarakat FEMA-IPB

\begin{abstract}
Teenage pregnancy may result poor birth outcomes, such as the risk of stunting, infant mortality, premature and Low Birth Weight ( $L B W$ ). This study aimed to determine the perceptions of high school girls in two different environments, namely rural and urban areas regarding teen pregnancy. The data included perceptions about nutrition and reproductive health, marriage and teen age pregnancy, premarital pregnancy, as well as nutrition and health during pregnancy. This study was conducted in SMA Negeri 1 Lewiliang, Bogor Regency and SMA Negeri 1 Bogor City with total subjects were six people. The result of this study showed a similar perception of the reproductive health of young women in both rural and urban area. Subjects from the countryside can still tolerate teenage marriage and pregnancy if there is readiness of teenagers. In contrast, the subjects in urban areas do not think of an excuse to get married in young age. Young women in the village can express more detail about food that should be consumed or avoided, including food relating to taboo. In addition, young women in the village can provide more in-depth opinion about health care during pregnancy.
\end{abstract}

Keywords : Perceptions of Young Women, Reproductive Health, Teen Pregnancy, Premarital Pregnancy, Nutrition

\section{PENDAHULUAN}

Masa remaja merupakan bagian dari proses tumbuh kembang, yaitu masa peralihan dari tahap kanak-kanak menuju tahap dewasa yang ditandai dengan pubertas karena terjadi reaktivasi sistem saraf pusat yang mengatur perkembangan seksual dan sistem reproduksi. Manifestasi awal pubertas adalah terjadinya percepatan pertumbuhan (Growth spurt). Growth spurt adalah sinyal pematangan sistem reproduksi (Bogin 1999). Hurlock (1980) memberi batasan masa remaja berdasarkan usia kronologis, yaitu antara 13 hingga 18 tahun. Namun menurut aliran kontemporer usia remaja antara 11 hingga 22 tahun 
(Thornburgh 1982). Pada masa remaja juga merupakan masa transisi dari segi psikologis, kognitif dan sosial dari perilaku kanak-kanak menuju dewasa. Oleh karena itu, remaja sangat rentan mengalami masalah psikososial, yakni masalah psikis atau kejiwaan yang timbul akibat perubahan sosial yang terjadi (Kipke 1999; Soejoeti 2001; Santrock 2003; Patton and Viner 2007).

Masa remaja juga dicirikan dengan banyaknya rasa ingin tahu dalam berbagai hal, tidak terkecuali bidang seks terkait dengan matangnya sistem reproduksi dan kemampuan menjalankan fungsi reproduksi. Meskipun demikian, hal ini tidak berarti bahwa remaja sudah mampu bereproduksi dengan aman secara fisik. Kecenderungan remaja saat ini memiliki pergaulan yang lebih bebas dibandingkan dengan remaja pada masa lalu akan berdampak pada semakin tingginya angka permasalahan remaja yang terkait dengan sistem reproduksi mereka terutama bagi remaja putri, salah satunya kehamilan. Selain itu, masyarakat rural dan tradisional masih mengijikan anak-anaknya menikah diusia remaja tanpa tahu resiko saat putri mereka harus hamil dan melahirkan.

Kehamilan pada usia remaja beresiko tinggi menghasilkan kelahiran yang buruk, salah satunya adalah resiko stunting. Prevalensi stunting di Indonesia saat ini cukup tinggi yakni 35,6\% (Riskesdas 2010). Ahmad (2004) menyatakan bahwa saat ini satu dari sepuluh kelahiran di dunia adalah dari ibu yang masih berusia kanak-kanak yakni 11-12 tahun. State of the World's Mothers (2004) melaporkan bahwa komplikasi persalinan kehamilan merenggut nyawa sekitar 70000 gadis remaja setiap tahun. Bayi yang lahir dari ibu yang berusia remaja memiliki resiko $50 \%$ lebih besar terhadap kematian serta cenderung premature dan mengalami Bayi Berat Lahir Rendah (BBLR).

Penelitian ini bertujuan untuk mengetahui persepsi remaja sekolah menengah atas di dua lingkungan yang berbeda yaitu pedesaan dan perkotaan mengenai kesehatan reproduksi, kehamilan di usia remaja, gizi ibu hamil, serta hal-hal yang melatarbelakangi persepsi tersebut.

\section{METODE PENELITIAN}

\section{A. Waktu dan Lokasi}

Penelitian ini dilakukan pada bulan April sampai Mei 2013 di SMA Negeri 1 Lewiliang, Kabupaten Bogor dan SMA Negeri 1 Kota Bogor. Analisis data dilakukan di Departemen Gizi Masyarakat, Fakultas Ekologi Manusia, Institut Pertanian Bogor.

\section{B. Subjek}

Subjek ditentukan secara purposif di kedua lokasi dengan jumlah subjek 3 orang pelajar putri untuk masing-masing lokasi. Ketiga subjek di masing-masing lokasi penelitian mewakili pelajar putri di dua kondisi 
lingkungan yang berbeda, yaitu pedesaan dan perkotaaan. Lingkungan pedesaan diwakili oleh subjek yang berasal dari SMA Negeri 1 Lewiliang, sedangkan lingkungan perkotaan diwakili oleh subjek yang berasal dari SMA Negeri 1 Bogor. Setiap subjek bersedia diwawancarai dengan menandatangai inform concern.

\section{Pengambilan Data}

Pengambilan data dilakukan melalui wawancara mendalam (Indepth interview) pada subjek mengenai persepsi mereka tentang kehamilan di usia remaja. Sebelum melakukan wawancara, dilakukan pendekatan dan habituasi dengan subjek. Jika subjek bersedia untuk diwawancarai maka subjek menandatangani informed concent. Masing-masing subjek diwawancari oleh satu peneliti dan direkam melalui voice recorder dan video recorder.

\section{Analisis Data}

Analisis data menggunakan teknik analisis isi (content analysis), yaitu membuat inferensi-inferensi yang dapat ditiru (replicable) dengan mem- perhatikan konteksnya. Analisis isi berhubungan dengan komunikasi atau isi komunikasi. Data ini akan dinarasikan apa adanya sesuai konteksnya dan akan di validasi.

\section{E. Validasi Data}

Data divalidasi menggunakan teknik triangulasi peneliti. Hasil rekaman wawancara yang telah diterjemahkan kedalam tulisan akan diverifikasi pada subjek oleh peneliti kedua dan seterusnya sampai diperoleh data yang valid. Data yang valid adalah rekapan data berupa tulisan yang ketika peneliti tunjukan kepada subjek, subjek menyatakan bahwa apa yang ditulis sudah benar.

\section{HASIL DAN PEMBAHASAN}

\section{A. Karakteristik Subjek}

Subjek yang di dapat dalam penelitian ini adalah remaja putri yang merupakan siswi SMAN 1 Leuwiliang dan SMAN 1 Bogor dengan rentang usia 16-17 tahun (Tabel 1). Persepsi mereka mewakili remaja di pedesaan dan diperkotaan.

Tabel 1. Identitas Subjek

\begin{tabular}{ccc}
\hline Kode & Asal & Usia (tahun) \\
\hline P1 & SMAN 1 Leuwiliang & 16 \\
P2 & SMAN 1 Leuwiliang & 17 \\
P3 & SMAN 1 Leuwiliang & 17 \\
Q1 & SMAN 1 Bogor & 16 \\
Q2 & SMAN 1 Bogor & 16 \\
Q3 & SMAN 1 Bogor & 16 \\
\hline
\end{tabular}

$\mathrm{P}=$ kode untuk subjek pedesaan; $\mathrm{Q}=$ kode untuk subjek perkotaan 


\section{B. Kesehatan Reproduksi}

Kesehatan reproduksi remaja adalah suatu kondisi sehat yang mencakup fungsi dan sistem reproduksi yang dimiliki oleh remaja. Pengertian sehat disini tidak semata mata berarti bebas penyakit atau bebas dari keca-catan namun juga sehat secara mental serta sosial kultural (Unicef 2005). Kesehatan reproduksi pada penelitian ini mencakup pada persepsi subjek terhadap arti dari menstruasi, perawatan daerah kewanitaan saat menstruasi serta pengetahuan tentang makanan tabu yang terkait dengan kesehatan reproduksi. Berikut ini persepsi subjek mengenai arti dari mestruasi :

“...menstruasi yang saya tahu itu batas dimana perempuan itu udah jadi baligh atau dewasa... kalau dari biologi sih terjadi karena sel ovum tidak dibuahi oleh sperma ..." (P1, Q1, Q2, Q3)

"...datang bulan, sudah dewasa, baligh..." (P2, P3)

"...harus jaga diri, hati-hati, tidak anehaneh..." (P1, P2, P3, Q1, Q2, Q3)

Persepsi subjek terhadap perawatan daerah kewanitaan saat menstruasi: “...jaga kebersihan, sering ganti pembalut..." (P1, P2, P3, Q1, Q2, Q3) "...pakai sabun pembersih khusus..." (Q3) “...kalau hari-hari biasa kalau ke sekolah pakai pantiliner, kalau di rumah mah ga pake ..." (P3)

Subjek pada penelitian ini mengerti mengenai apa yang dimaksud dengan menstruasi dan bagaimana merawat kebersihan daerah kewanitaan. Mereka juga mampu mengingat kapan pertama kali mereka menstruasi (menarke) (Tabel 2). Hal ini menunjukkan bahwa mestruasi memiliki makna yang penting untuk siklus hidup mereka. Menurut subjek, menstruasi itu menandakan usia semakin dewasa atau baligh, sehingga harus lebih bisa menjaga hubungan dengan lawan jenis. Persepsi yang diungkapkan oleh remaja ini menandakan bahwa remaja secara mental telah mengetahui dan siap dengan perubahan-perubahan dalam siklus kehidupannya. Selain itu, mereka juga mengetahui bagaimana cara untuk merawat daerah kewanitaan terutama saat menstruasi. Mereka beranggapan bahwa saat menstruasi daerah kewanitaan harus dijaga agar tidak lembab dengan sering mengganti pembalut.

Tabel 2. Usia Menstruasi Pertama (Menarke) Subjek

\begin{tabular}{clc}
\hline Kode & \multicolumn{1}{c}{ Asal } & Usia menarke (tahun) \\
\hline P1 & SMAN 1 Leuwiliang & 10 \\
P2 & SMAN 1 Leuwiliang & 12 \\
P3 & SMAN 1 Leuwiliang & 15 \\
Q1 & SMAN 1 Bogor & 11 \\
Q2 & SMAN 1 Bogor & 12 \\
Q3 & SMAN 1 Bogor & 11 \\
\hline
\end{tabular}


Pengetahuan tentang kesehatan reproduksi menjadi sesuatu yang sangat penting bagi remaja putri. Media memiliki potensi besar dalam mengubah sikap dan perilaku masyarakat, terutama anak-anak yang relatif masih mudah terpengaruh dan dipengaruhi.

Ketika ditanyakan seputar masalah makanan tabu subjek menanggapinya dengan pernyataan berikut:

“..ada yang bilang juga karena nanas itu telalu asam takut ngerusak rahim...tapi ada yang bilang juga kalau pisang ambon tuh justru baik buat perkembangan wanita....Kalau lagi mens itu ga boleh makan timun katanya nanti suka keputihan jadi banyak..."(P1)

"...tidak boleh makan pedes-pedes dan cuka karena perut jadi tambah sakit.., tidak boleh makan coklat karena mensnya bisa jadi tambah banyak.." (P2) "...ga boleh minum es atau yang dingin-dingin...bikin mampet darahnya, bikin sumilangen..." (P1, P3)

"...tidak boleh minum soda karena mensnya jadi banyak..." (Q1, Q2, Q3) “...tabu es..pernah dengar, ga enak aja diperut..."(Q2)

Lima dari 6 subjek beranggapan bahwa meminum obat-obatan khusus penghilang rasa sakit saat menstruasi adalah tidak baik. Dua subjek di pedesaan (P1, P3) dan 1 subjek di perkotaan (Q2) beranggapan bahwa saat menstruasi tidak boleh minum air es namun dengan alasan yang berbeda. Subjek dipedesaan lebih mengenal makanan tabu dibandingkan subjek di perkotaan. Tingkat pengetahuan yang berbeda mengenai makanan tabu di dua lingkungan mungkin dikarenakan lingkungan di pedesaan lebih sering memelihara budaya tabu. Pengetahuan ini diturukan dari orang tua ke generasi berikutnya kemudian begitu seterusnya. Subjek dipedesaan mengetahui hal ini mungkin dikarenakan interaksi dengan lingkungan sosial yang lebih intensif dibandingkan subjek diperkotaan. Hal ini mungkin juga dikarenakan kehidupan masyarakat kota yang sudah mulai tidak percaya mengenai tabu dan lebih modern.

Hasil telaah Saptandari (2012) menunjukkan bahwa pandangan, pemahaman serta kepercayaan masyarakat tentang tubuh, seksualitas dan kesehatan perempuan berkontribusi terhadap kerentanan tubuh dan kesehatan reproduksi perempuan, serta menguatnya wacana tubuh serta medikalisasi terhadap tubuh perempuan.

\section{Persepsi Remaja Mengenai Per- nikahan dan Kehamilan di Usia Remaja}

Penelitian ini mencakup persepsi subjek tentang pernikahan dan kehamilan usia remaja, serta usia ideal pernikahan dan kehamilan. Berikut persepsi subjek terhadap pernikahan usia remaja:

“....kurang setuju ya sama yang kayak gitu...ada masanya lah..masa dia kan masa remaja..kalau sepertinya.. dipake buat ngurus anak..keteteran juga..." (P1) 
“..tidak apa - apa sih, yang penting siap lahir batin, lahir itu..sudah punya gaji, batinnyaitu...cinta..." (P2)

"..nikah kan ga gampang, pemikirannya harus udah dewasa.."(P3)

"...saya ga setuju, pendidikan dulu yang penting, sebagai bekal untuk mengurus keluarga.." (Q1)

“..ga setuju, soalnya dari sifatnya juga dia belum dewasa belum bisa bertanggungjawab kan.." (Q2)

“..ngapain gitu loh? masih muda muda emang ngerti yang seperti itu, karir masih panjang.., masih bisa cari banyak ilmu.."(Q3)

Persepsi tentang kehamilan di usia remaja:

“...rahimnya juga kan belum terlalu kuat...resikonya lebih besar juga..." (P1) "..tidak apa hamil di usia remaja, tapi sebaiknya tidak langsung hamil, tapiada jarak sekitar 1 tahunan.."(P2)

“..kurang siap di reproduksi kata $B$ mah.., pernah ada kasus yang hamil umur 12 tahun akhirnya meninggal, katanya sih belum kuat melahirkan.." (P3)

"...tidak masalah, asalkan hamil karena menikah..., bukan karena freesex....tapi kalau secara pribadi saya tidak setuju karena umur segitu masih labil, rahim masih belum kuat, kematangan perempuan bertahap semakin tambah usia semakin matang..." (Q1)

"...ga setuju.., organ dalam dia belum matang.." (Q2)

"... tidak baik hamil di usia ramaja karena masih anak-anak, belum dewasa, masih sekolah, masih anak kecil juga, mending sekolah dulu.." (Q3)
Subjek di perkotaan maupun desa pada penelitian ini mempunyai persepsi bahwa pernikahan maupun kehamilan pada usia remaja sebaiknya dihindari, dengan berbagai alasan antara lain pada usia ini dianggap belum dapat bertanggung jawab, organ reproduksi belum matang dan dianggap sebagai sesuatu yang tabu. Persepsi ini menunjukkan bahwa remaja sudah mengerti dampak negatif dari pernikahan pada usia remaja, sehingga pernikahan diusia remaja sebaiknya dihindari.

Sebuah systematic review yang dilakukan oleh Cunnington (2001) mengidentifikasi bahwa pernikahan usia remaja mempunyai konsekuensi medis, seperti anemia, hipertensi yang dipicu oleh kehamilan, berat bayi lahir rendah, bayi lahir secara prematur, Intra Uterine Growth Retardation (IUGR), dan kematian neonatal. Peningkatan risiko ini sebagian besar disebabkan oleh faktor-faktor sosial, ekonomi, dan perilaku ibu muda yang mengalami kehamilan. Usia ibu yang kurang dari 16 tahun akan berisiko 1.2-2,7 kali lipat dalam peningkatan terjadinya prematuritas, BBLR dan kematian neonatal.

Pernikahan pada usia remaja menurut penelitian UNICEF tahun 2005 tampaknya berhubungan pula dengan derajat pendidikan yang rendah. Hasil kajian UNICEFf pada beberapa negara di dunia, disebutkan pula bahwa faktor ekonomi menjadi salah satu alasan orang tua menikahkan anaknya pada 
usia remaja. Hal ini terbukti dengan adanya pernyataan dari subjek (P1) bahwa :

"...yang nikah diusia remaja itu kan mereka juga pasti ada pilihan...kerena apa?...tidak meneruskan...keterbatasan biaya...jadi mau ga mau...mau ngapain lagi...sekolah juga engga...kerja juga engga...namanya juga perempuan ya tinggal nungguin jodoh...".

Kadang kala menikahkan anak diusia remaja menjadi alternatif untuk memindahkan tanggung jawab terutama nafkah kepada pasangan. Padahal, menurut Mwaba (2000) remaja yang menikah diusia muda dan tidak bersekolah akan mengalami gangguan dalam karir dan ekonomi yang rendah. Hasil penelitian di Nepal menunjukkan bahwa orang tua di pedesaan memiliki andil yang besar dalam menentukan waktu pernikahan bagi anakanaknya dibandingkan diperkotaan yang menyerahkan keputusan kepada anak-anaknya (Choe et al. 2004).

Bagi subjek usia ideal untuk pernikahan adalah berkisar 21-27 tahun. Berikut persepsi tentang usia ideal pernikahan dan kehamilan:

"...tergantung karir... nikah umur $26 . .27$, hamil ...27... umurnya juga cukup mateng...rahimnya juga udah cukup kuat...mentalnya juga udah cukup kuat, udah mulai bisa memanage diri juga..." (P1)

"..21-22 tahun, misalnya nikah usia 22 tahun yah hamilnya usia 23 tahun." (P2) “...usia 24-25 tahun.."(P3)

“...25 tahun, sudah lulus kuliah, sudah menemukan jatidirinya, sudah cukup dewasa..." (Q1)

“...usia ideal 27 tahun..sudah dewasa, bisa menjaga kehamilan dan organ reproduksi sudah matang.." (Q2)

"...ga tau.., kayaknya sih nikah ideal umur 25-27 tahun yah.., kalau hamil ideal ya setelah nikah, tapi kalau nikahnya seumuran saya trus langsung hamil ya jangan begitu juga.."(Q3)

Persepsi tersebut menunjukkan bahwa subjek baik di kota maupun di desa telah memilki persepsi yang hampir sama tentang usia pernikahan yang ideal. Hal ini dikarenakan subjek mengganggap bahwa pendidikan dan karir yang mapan merupakan hal yang penting dicapai sebelum menikah. Hal ini menunjukkan terdapat korelasi antara tingkat pendidikan dan usia saat menikah, semakin tinggi pendidikan maka usia menikah relatif lebih tinggi. Pesepsi bahwa pendidikan dan karier yang mapan adalah hal yang harus dicapai sebelum menikah sebenarnya dapat menjadi solusi yang tepat bagi pemerintah dalam menurunkan angka kehamilan pada remaja, yakni dengan menetapkan wajib belajar 12 tahun, sehingga anak-anak akan terpacu untuk menyelesaikan sekolah hingga tingkat SMA, setelah lulus usia mereka sudah cukup siap untuk pernikahan dan kehamilan. 


\section{Persepsi Kehamilan Remaja Pranikah}

Kehamilan remaja pranikah mencakup persepsi tentang konsekuensi psikologis remaja yang hamil pranikah, pandangan masyarakat, keluarga dan peer grup subjek. Berikut persepsi tentang konsekuensi psikologis remaja yang hamil pranikah :

“...secara mental pasti belum siap..." (P1)

"...pasti berat beban mentalnya.., apalagi kalau cowoknya ga bertanggungjawab.." (P2)

"...pasti malu, di awal-awal ketahuan hamil biasanya hanya diam dirumah aja.." (P3)

“..pasti tekanan batin..., tapi tergantung orangnya.., yang tidak bisa menerima bisa jadi menyesal dan akan melakukan hal-hal yang tidak diinginkan seperti aborsi.." (Q1)

"..pasti dia ngerasa menyesal juga, udah gitu batinnya tertekan gitu sama masyarakat luar.." (Q2)

"...mungkin stress kayaknya.., dijauhin, dikucilin sama tementemen..." (Q3)

Pada dasarnya subjek beranggapan bahwa remaja yang hamil pranikah cenderung akan mengalami stress dan beban mental. Ada perasaan menyesal dan akan terkucilkan dimasyarakat. Karena menurut subjek masyarakat akan berpandangan sebagai berikut:

"...biasanya dinikahkan agar pandangan masyarakat tidak negatif, kalau sembunyi-sembunyi masyarakat curiga..." (P1)

“...Kalau sepertinya udah lama pasti biasa lagi, tapi kalau awal-awal memang kayak gitu...sikap masyarakat berubah..cuma ngomongin aja.." (P1) "...yang pasti dia dikucilkan dan diomongin orang-orang terutama ibuibu.." (P2)

“..di kampung B mah udah sering...jadi udah biasa gitu..biasanya jadi bahan obrolan dan cibiran ibu-ibu.., tapi hanya dibelakang anaknya, tidak secara langsung.." (P3)

"..masyarakat akan berpikiran negative padanya dan keluarganya.." (Q1)

"..kayak diomongin di belakang..respon pertama kan kokbisa kayak gitu..pas dia lewat dia diomongin gitu.." (Q2)

"..hina sepertinya...tidak baik.." (Q3)

Subjek juga menyatakan persepsinya jika hal itu terjadi dalam keluarga, maka remaja yang mengalami hamil pranikah akan mengalami hal sebagai berikut:

“...pasti ada yang marah dan tidak mengangap saudara, orang tua pasti menutup-nutupi kejadian itu agar tidak malu dengan keluarga lain.."' (P1) "...misalnya ada yah..harus disemangatin, karena takut digugurin kandungannya.." (P2)

"..dinasehatin di depan anaknya.. kalaupun dinikahkan seharusnya setelah melahirkan dinikahkan lagi agar pernikahannya sah.." (P3)

"..awalnya mungkin terjadi perdebatan, selanjutnya mungkin keluarga akan menerima dan mendukung.." (Q1) "..tanya cerita selangkapnya biar ga ada salah paham..namanya keluarga mau ga 
mau harus terima, mungkin kalau keluarga mandangnya ga akan negatifnegatifamat.." (Q2)

"..tidak apa-apa sudah lewat, yang penting kedepannya tidak dilakukan lagi... ga usah berhubungan lagi.." (Q3)

Dari persepsi di atas dapat dilihat bahwa keluarga subjek akan memberi kesempatan kepada keluarganya yang hamil pranikah untuk memperbaiki kesalahannya walaupun pada awalnya terjadi perdebatanperdebatan diantara anggota keluarga. Selain itu, subjek juga mengutarakan bahwa pandangan peer grup terhadap kehamilan pranikah tidak jauh berbeda dengannya:

“...teman-teman pada ilfeel...karena gaulnya salah..kita gaulnya tidak seperti mereka.." (P1)

"..teman deket tiga orang, semuannya punya pacar..saya ga boleh pacaran...tapi kayaknya mereka juga ga setuju.."(P2)

"..temen-temen B kayaknya sama ya, tidak setuju kalau hamil di usia remaja.., B ga suka pacaran..ga tau..geli.."(P3) "..saya berteman dengan 5-10 teman, sebagian besar pacaran, tapi pikiran mereka kayaknya sama dengan saya.." (Q1)

"..temen-temen tuh udah sering nonton acara luar negeri gitu..kalau luar negeri mereka mewajarkan..tapi kalau disini masih negative...dan ga wajar.." (Q2) ".ga terlalu jauh dengan pandangan saya...itu tidak benar..tapi selama masih mau maju..., tidak akan mengulanginya pasti akan diterima lagi.." (Q3)
Menurut subjek, remaja yang mengalami kehamilan pranikah akan mengalami tekanan psikologis. Penolakan yang dilakukan oleh orang tua, sekolah dan teman-teman merupakan pukulan berat bagi remaja. Lingkungan sekitar juga akan melakukan pengucilan dan akan terus mengingatkan sebagai remaja yang pernah hamil di luar pernikahan. Rasa malu, perasaan bersalah dan menyesal akan bercampur dengan perasaan takut dan cemas dalam menjalani masa kehamilan. Menurut subjek, peran orang tua sangat penting untuk membangun kembali semangat dan kepercayaan diri anak, sehingga mengurangi efek negatif kehamilan di luar nikah ini. Efek negatif yang mungkin dapat muncul adalah depresi yang dapat berujung pada bunuh diri atau aborsi.

Tabel 3. Aktifitas Ekstrakulikuler Subjek

\begin{tabular}{cl}
\hline Kode & Aktifitas/organisasi \\
\hline P1 & OSIS \\
P2 & Rohis \\
P3 & Pencinta Alam \\
Q1 & OSIS \\
Q2 & PMR \\
Q3 & Olahraga \\
\hline
\end{tabular}

Persepsi subjek dimungkinkan merupakan hasil dari pengajaran, diskusi maupun interaksi yang dilakukan dengan teman ataupun keluarganya. Oleh karenanya persepsi peer group subjek akan sama dengan 
subjek. Seluruh subjek pada penelitian ini mengikuti kegiatan ekstrakulikuler sehingga interaksi dengan peer group lebih intensif (Tabel 3).

Selain itu, norma dan nilai-nilai agama yang dianut oleh keluarga, disampaikan secara langsung oleh ibu. Konsep hubungan dengan lawan jenis atau pacaran disampaikan secara jelas oleh ibu dari para remaja ini, baik yang tinggal di perkotaan maupun pedesaan. Hal ini tertuang dalam pernyataan sebagai berikut:

"...sering dinasehatin...masih kecil tugasnya itu belajar jangan dulu pacarpacaran kayak gitu..." (P1)

"...Ibu membatasi pergaulan B dengan anak-anak kampung, tidak boleh pacaran..." (P3)

"...Saya gak boleh pacaran dulu oleh ibu sebelum kuliah dan kerja. Jadi kuliah dan kerja dulu baru menikah. Gak usah pacaran tapi taarufsaja seperti bibi-bibi saya juga seperti itu...." (P2)

"...Saya tidak pernah dilarang pacaran juga tidak pernah dianjurkan punya pacar. Tapi menurut saya mama tidak senang jika saya pacaran karena pasti akan sering keluar rumah..." (Q1)

“..aturan rumah ketat..." (Q2)

"...Seminggu sekali ada guru ngaji kerumah..." (Q3)

Dari beberapa pernyata tersebut jelas bahwa orangtua memegang peranan penting dalam pembentukan perilaku remaja, karena orangtua merupakan lingkungan pertama dan utama yang mempunyai hubungan paling intensif dengan anak. Oleh karena itu, sebelum mengenal normanorma dan nilai-nilai dari masyarakat umum, anak akan menyerap normanorma dan nilai-nilai yang berlaku dalam keluarganya terlebih dahulu. Norma atau nilai itu dijadikan bagian dari kepribadiannya. Semua itu pada hakikatnya ditimbulkan oleh norma dan nilai yang berlaku dalam keluarga, yang diturunkan melalui pendidikan dan pengasuhan orang tua pada anakanak secara turun-temurun. Norma dan nilai yang dianut keluarga harus disampaikan secara tegas dan jelas, sehingga anak-anak tidak ragu atau bingung pada saat mengambil keputusan yang berkaitan dengan norma dan nilai tersebut. Jika tidak disampaikan secara jelas, maka anak akan cenderung mencari informasi tersebut melalui teman sebaya atau media lainnya yang mungkin akan berakibat negatif. Hal ini mungkin juga terkait dengan latar belakang orang tua subjek. Choe et al. (2004) menyatakan bahwa tingkat pendidikan ayah dan ibu berkorelasi dengan pernikahan diusia muda dipopulasi manapun, dengan pengecualian remaja dikota dari orang tua berpendidikan rendah akan memilih bekerja dibanding menikah untuk menghidup keluarganya.

Latar belakang pendidikan orang tua subjek seluruhnya memiliki pendidikan e" 9 tahun. Orang tua subjek di perkotaan seluruhnya berpendidikan hingga ke perguruan tinggi, sedangkan di pedesaan terdapat 
satu subjek yang pendidikan orang tuanya tidak sampai ke perguruan tinggi (Tabel 4). Sehingga wajar saja jika pada persepsi waktu menikah yang ideal mereka mementingkan pendidikan dan karir terlebih dahulu.

Remaja juga perlu menyadari akan pentingnya pembuatan keputusan untuk menolak setiap kegiatan seksual yang rentan terjadi pada masa remaja karena setiap kegiatan seksual mempunyai risiko negatif tentang kesehatan reproduksinya. Hubungan atau kontak seksual pada remaja di bawah 16 tahun juga berisiko terhadap tumbuhnya sel kanker pada mulut rahim, penyakit menular seksual, HIV/ AIDS, melakukan aborsi, dan lebih jauh dapat menyebabkan komplikasi berupa ganguan mental dan kepribadian pada remaja (Unicef 2005).

Tabel 4. Latar Belakang Keluarga Subjek

\begin{tabular}{lcccll}
\hline \multirow{2}{*}{ Kode } & $\begin{array}{c}\text { Subjek anak ke- } \\
\text {...dari...saudara }\end{array}$ & \multicolumn{2}{c}{$\begin{array}{c}\text { Pendidikan } \\
\text { orang tua }\end{array}$} & \multicolumn{2}{c}{ Pekerjaan orang tua } \\
\cline { 3 - 6 } & Ayah & Ibu & \multicolumn{1}{c}{ Ayah } & \multicolumn{1}{c}{ Ibu } \\
\hline P1 & 2 dari 3 & S1 & SMA & Kepala Sekolah SD & IRT \\
P2 & 2 dari 6 & S1 & S1 & Guru & Guru \\
P3 & 2 dari 3 & SMA & MTS & Mandor perkebunan & IRT dan Wirausaha \\
Q1 & 3 dari 3 & S3 & S2 & Pegawai Dept.Pertanian & Dosen \\
Q2 & 2 dari 3 & S1 & S2 & Pegawai BUMN & Guru SMA \\
Q3 & 3 dari 3 & S3 & S3 & Dosen & Dosen \\
\hline
\end{tabular}

\section{E. Persepsi Remaja tentang Kebu- tuhan Gizi dan Kesehatan Selama Kehamilan}

Ibu hamil membutuhkan asupan gizi yang seimbang. Kesimbangan itu diperlukan agar tidak ada zat gizi yang berlebihan, bahkan kurang. Kebutuhan gizi dan kesehatan selama kehamilan akan menentukan outcome kehamilan dan akan memberikan dampak jangka panjang pada anak yang dilahirkan. Kekurangan gizi pada ibu hamil dapat beresiko melahirkan bayi BBLR, kematian neonatal dini (kurang dari satu minggu setelah dilahirkan), serta rendahnya status gizi bayi sampai dengan umur 9 tahun (Sandjaja 2009). Persepsi remaja tentang kebutuhan gizi dan kesehatan selama kehamilan meliputi persepsi tentang kebutuhan gizi selama kehamilan, makanan tabu dan perawatan kehamilan.

Berikut persepsi tentang kebutuhan gizi saat hamil :

"...minum susu ibu hamil, makan lebih
bnyak porsinya.."(P1)
"..banyak makan sayur-sayuran dan
buah-buahan untuk nutrisi bayi..juga
makan makanan laut seperti udang
untuk kecerdasan anak.." (P2)

“...minum susu ibu hamil, makan lebih bnyak porsinya.."(P1)

".banyak makan sayur-sayuran dan buah-buahan untuk nutrisi bayi..juga untuk kecerdasan anak.." (P2) 
“..makan makanan yang berprotein tinggi kayak ikan-ikanan gitu.. pokoknya 4 sehat 5 sempurna.." (P3) "...minum susu, makan daun katuk biar asinya nanti banyak, tidak boleh minuman bersoda, tidak boleh gorengan karena banyak minyak.." (Q1)

"...harus banyak makan makanan bergizi dan bernutrisi juga...makan daun katuk, makan sayur..makan buah.." (Q2)

"...ga tau..taunya hanya ga boleh minum obat-obat, harusmakan makanan yang sehat alami...ga boleh yang terlalu banyak lemak, atau makanan yang mengandung pewarna, zat aditif.." (Q3)

Berikut persepsi tentang makanan tabu:

“...tidak boleh merokok, makan jenis ragi bikin cacat pada bayi, makanan pedas, minum alcohol, nanas bikin panas.."(P1) ".gak boleh minum air es, karena akan menyebabkan besar, tapi saya ga tau apanya yang besar..., sprite dan cocacola ga boleh, tapi ga tau alasannya kenapa, durian karena katanya banyak gasnya, daging kambing karena panas dan darah tinggi.., mkan jangan di piring besar tapi pakai pisin.." (P2)

"..banyak makan katuk biar lancar melahirkan.., ga boleh makan nanas karena takut gugurin kandungan.., ga boleh makan durian dan ekstrajoss.., ga tau kenapanya mah..denger-denger selewat aja sih.." (P3)

"..ga boleh makan nanas.., tapi ga tau alasannya kenapa.." (Q1)

"..ga tau..,ga pernah denger.." $(\mathrm{Q} 2, \mathrm{Q3})$

Berikut persepsi tentang perawatan kehamilan: "...tidak boleh cape, harus tidur teratur, tidak boleh stress, harus senang, olahraga.." (P1)

"...harus jaga sikap..ucapannya jadi jangan ngomong sembarangan.." (P2) "...ga boleh terlalu capek..tapi ga baik juga kalo diam aja tidak beraktifitas.., ga boleh melilitkan sesuatu di leher..biar bayinya ga kelilit ari-ari.., kakau ngidam harus diturutin.." (P3)

"..ga boleh pake pakaian yang ketat, kasihan banyinya..harus jaga kebersihan, ikut senam hamil, jangan duduk ngangkang khawatir lahir premature.." (Q1)

"...harus banyak istirahat jangan terlalu cape, udah gitu jangan pake baju yang terlalu ketat, olahraga teratur.." (Q2)

“..harus menjaga kebugaran..tetap olahraga menggerakkan tubuh..tapi jangan yang terlalu ekstrim juga.." (Q3)

Dari penunturan subjek diatas diketahui bahwa pengetahuan mereka mengenai kebutuhan gizi dan perawatan masa kehamil belum memadai terutama untuk subjek diperkotaan. Subjek di desa menyampaikan pendapatnya yang berkaitan dengan gizi ibu hamil lebih rinci dibandingkan dengan remaja di kota yang hanya sebatas makan yang bergizi, alami dan minum susu. Tentang kebutuhn akan vitamin dan makan dengan porsi yang lebih banyak juga disampaikan oleh remaja di desa. Demikian pula dalam hal perawatan kesehatan selama kehamilan, remaja di desa lebih banyak memberikan jawaban yang rinci dibandingkan dengan remaja kota. Seperti tidak boleh terlalu lelah, 
menjaga makanan, tidak boleh stres, tidur teratur dan olah raga/senam hamil adalah hal-hal yang sebaiknya dilakukan ibu untuk menjaga kesehatannya. Remaja di desa juga lebih banyak mengenal tabu-tabu yang berkenaan dengan kehamilan, seperti tidak boleh keluar sesudah magrib, makan sebaiknya menggunakan "pisin" (piring kecil), tidak boleh makan nanas, makanan pedas, minuman beralkohol dan bersoda dan durian. Hal ini mungkin terkait dengan sistem kekeluargaan didesa lebih dekat dibandingkan diperkotaan, seperti sering berinteraksi dengan saudara maupun tetangga, sehingga pengetahuan mereka mengenai perawatan, gizi, dan makanan tabu ibu hamil lebih banyak.

\section{KESIMPULAN}

Subjek di desa maupun dikota mempunyai persepsi yang sama mengenai kesehatan reproduksi terutama menstruasi. Sedangkan untuk persepsi pernikahan dan kehamilan diusia remaja, subjek di kota dengan tegas menyatakan tidak setuju, sedangkan subjek di desa meskipun tidak setuju tapi mentolelir jika pernikahan remaja merupakan pilihan karena remaja tersebut tidak besekolah. Persepsi tersebut mungkin dilatar belakangi oleh pendidikan norma dan nilai-nilai moral yang ditanamkan oleh keluarga terutama oleh ibu. Selain itu, mereka menyadari bahwa dalam kondisi hamil seseorang hendaknya menjaga gizi dan menghindari hal-hal yang tabu. Subjek di desa dapat mengutarakan lebih rinci perihal makanan yang sebaiknya dikonsumsi atau dihindari, termasuk hal-hal yang berkenaan dengan tabu, serta cara-cara perawatan kesehatan selama hamil. Hal ini dimungkinkan faktor kedekatan/interaksi dengan tetangga serta lingkungan pedesaan yang masih memelihara tabu dibandingkan lingkungan perkotaan yang lebih modern dan individualistik.

\section{DAFTAR PUSTAKA}

Ahmad K. 2004. Pregnancy Complication Kill 70,000 Tenagers a Year. Lancet; 15; 363,9421, p 1616

Bogin B. 1999. Pattern of Human Growth. Ed ke-2. Cambridge : Cambridge Univ Press.

Choe MK, Thapa S, Mishra V. 2004. Early Merriage and Early Motherhood in Nepal. J. biosoc. Sci. (First Published online 2004) 00:1-20. 
Cunnington, AJ. 2001. What's so Bad About Teenage Pregnancy? The Journal of Family Planning and Reproductive Health Care: 27(1): 36-41

Hurlock, E.B. 1980. Psikologi Perkembangan. Edisi kelima. Penerbit Erlangga. Jakarta

Kipke MD. 1999. Adolescent Development and The Biology of Puberty: Summary of a workshop on new research. Washington D.C : National Acedemy Press.

Mwaba K. 2000. Perceptions of Teenage Pregnancy Among South African Adolescents. Healths Age Sondheim 5(3):30-34.

Notoadmodjo, S. 2010. Ilmu Perilaku Kesehatan.: Rineka Cipta. Jakarta

Patton GC, Viner R. 2007. Adolescent Health 1: Pubertal Transition Health. The lancet 369: 1130-1139.

Pinky Saptandari. 2012. Kesehatan Reproduksi Perempuan dalam Perspektif Antropologi Budaya. BioKultur, Vol.I (1):1-18.

Riskesdas. 2010. Riset Kesehatan Dasar. Badan penelitian dan pengembangan kesehatan Kementerian kesehatan RI. Jakarta

Sandjaja. 2009. Risiko Kurang Energi Kronis (KEK) Pada Ibu Hamil di Indonesia Gizi Indonesia, 32(2):128-138.

Santorck JW. 2003. Adolescence: Perkembangan Remaja. Ed ke-6. Jakarta: Erlangga.

Soejoeti SZ. 2001. Perilaku Seks Dikalangan Remaja dan Permasalahannya. Media Litbang Kesehatan 11(1):30-35.

State of the World's Mothers. 2004. Children Having Children. David and Lucile Packard Foundation. ISBN 1-888393-16-5.

Thornburg, H.D. 1982. Developmental Psychology. 2nd ed. Monterey, California: Brooks and Cole Publishing Company. 